\title{
Toward a Sustainable University: Babes-Bolyai University Goes Green
}

\author{
Gianluca Zanellato and Adriana Tiron-Tudor *D
}

check for updates

Citation: Zanellato, Gianluca, and Adriana Tiron-Tudor. 2021. Toward a Sustainable University: Babes-Bolyai University Goes Green. Administrative Sciences 11: 133. https://doi.org/ 10.3390/admsci11040133

Received: 25 July 2021

Accepted: 1 November 2021

Published: 12 November 2021

Publisher's Note: MDPI stays neutral with regard to jurisdictional claims in published maps and institutional affiliations.

Copyright: (C) 2021 by the authors Licensee MDPI, Basel, Switzerland. This article is an open access article distributed under the terms and conditions of the Creative Commons Attribution (CC BY) license (https:// creativecommons.org/licenses/by/ $4.0 /)$.
Faculty of Economics and Business Administration, Babes-Bolyai University, Strada Teodor Mihali, Nr. 58-60, Campus FSEGA, 400591 Cluj-Napoca, Romania; gianluca.zanellato@econ.ubbcluj.ro

* Correspondence: adriana.tiron@econ.ubbcluj.ro

\begin{abstract}
The present research aims to investigate the roadmap followed by a Romanian University implementing sustainability practices and thus contributing to the United Nations Sustainable Development Goals. Informed by the stakeholder theory lens, the study contributes to the literature by exposing, from a longitudinal perspective, the case of the evolving commitment toward a more sustainable future by Babes-Bolyai University. In order to provide empirical results relevant to the literature, the investigation followed a combination of qualitative methodologies oriented to demonstrate how the institution approaches the recently developed sustainable development goals. Informed by the stakeholder theory, the research represents one of the first studies focusing on university SDG disclosure. Despite the modest recognition of Romanian HEIs in international rankings, the present study outlines a convinced commitment and a clear pathway, of BBU, toward a more sustainable future. Our research's originality relies on the selected institution and the university's policies with the SDGs. The study provides fresh knowledge in the growing debate of SDGs and HEIs and outlines how such institutions can contribute toward sustainable development goals through means already available.
\end{abstract}

Keywords: sustainable development goals; universities; case study; strategies; reporting

\section{Introduction}

Debates on a more sustainable future and the first steps in this regard begin with the publication of the Brundtland Report, which defines the concept of sustainable development (SD) as: "development that meets the needs of the present, without compromising the ability of future generations to solve their own" (UNWCED 1987) (p. 37). These debates are extremely current, as nowadays, the synergy of environmental, social, poverty, and violence issues puts humanity in the face of unprecedented challenges (Waas et al. 2010). In this context, more and more governments and organizations have begun to raise concerns about SD. In particular, the United Nations (UN) issued in 2015 a set of 17 sustainable development goals (SDGs) meant to guide countries towards development, a sustainable future from an economic, social, and environmental point of view (UN 2015). In supporting this approach, universities are expected to play an essential role, especially by educating future generations about SD (Sedlacek 2013).

The significant changes produced in society have also caused profound changes at the universities' level (Dabija et al. 2014), affecting the educational offer's objectives and the interaction with the community. Accordingly, Universities have been called to become sustainable and competitive through the three missions they carry out and connected to the demands of society, of the different stakeholders with whom they interact (Gamage and Sciulli 2017; Nicolò et al. 2021a). Thus, they began to make organizational changes to include sustainability in their core values (Owens 2017) and degree programs and curricula (Nicolò et al. 2021a; Owens 2017; Sassen and Azizi 2018). Accordingly, the literature on HEIs (higher education institutions) is mainly focused on corporate social responsibility 
(CSR) and sustainability reporting (SR) (Gamage and Sciulli 2017; Nicolò et al. 2021a; Sassen and Azizi 2018).

According to Waas et al. (Waas et al. 2010), there is an urgent need to research practices that HEIs are undertaking in order to contribute to SD. Furthermore, according to Gamage and Sciulli (2017), there is a need to investigate, from a longitudinal perspective, how HEIs are reporting and embracing the sustainability reporting issue. Thus, the present research focuses on implementing the SDGs in the case of an HEI and how such an organization contributes to the entrepreneurs' development, aware of the relevance of the SD (Wakkee et al. 2019). In this sense, the research outlines what type of activities the analyzed organization has established and promoted in order to prepare future entrepreneur generations. Furthermore, given their role in societies, HEIs are expected to deliver not only new graduates (teaching and learning) year by year, but these organizations are also expected to contribute to scientific advancement (research) and contribute to the environment in which they operate (community service). In this context, the adoption of the SDGs, through their omni-comprehensive essence (social and environmental), can play a crucial role in demonstrating how HEIs comply with societal expectations. Thus, different stakeholders are scrutinizing HEIs and their activities and are expecting responses by such organizations that will meet their expectations in relation to a wide range of aspects (e.g., social and environmental). Therefore, the investigation of how HEIs adapt their activities to face the expectations of a wide range of stakeholders shows how these organizations respond to external expectations and pressures.

In addition, by investigating the practices of universities on sustainability, Puertas and Marti (2019) highlighted that Romanian universities have a low commitment to sustainability issues compared to universities in other countries. At the time of this writing, only a few investigations focus on HEIs contribution toward the SDGs. Accordingly, the observation of how Universities adapt to new challenges and changes (Jacob et al. 2003; Youtie and Shapira 2008) represents an important issue that can provide fresh knowledge and serve as an exemplification for similar organizations.

Consequently, the research question driving the present research is: How did BabesBolyai University start to contribute toward the SDGs, and how does it contribute to the propagation of the goals?

In this context, the paper aims to investigate the sustainability strategies, from a longitudinal perspective, implemented at the organizational level by the Babes-Bolyai University (BBU) to improve their relations with the company and other stakeholders. The paper presents particular aspects with strong practical validities. The investigated university has a solid commitment to SDGs, is present in the international rankings and networks dedicated to sustainability issues and has a public strategy of its own that includes the three education-research-relationship missions with the community of a university of excellence. In addition, the investigated organization includes in its study program several courses related to sustainable development.

The remainder of this paper is composed as follows. The second section analyses debates in the specialized literature on SD, the evolution of SDGs, and their connection with the university environment and finally establish the paper's theoretical framework. The third section is dedicated to the methodology with the research design, the motivation of the HEI selected, and the data used in the study. The fourth section presents the research results and the discussions on them, and the last part contains the conclusions, limitations, and future developments.

\section{Literature Review and Theoretical Framework}

\subsection{Sustainable Development}

The SD issue has seen growing worldwide attention, as the overuse of natural resources by current generations affects the future of the next generations to meet their own needs (UNWCED 1987). Nowadays, humans are tackling the planet equilibrium, 
as our activities have already degraded around $60 \%$ of the world's ecosystem, and the degradation is not stopping (Barkemeyer et al. 2014).

The issue of SD is no matter of novelty; according to Bebbington (2001), "McCormick in (1986, at p. 178)" (p. 5) observed the existence of SD idea already under the Roosevelt administration and in the 1949 UN Scientific Conference on the Conservation and Utilisation of Resources.

However, the relevance of SD has constantly been increasing during the latest decades. In particular, in the year 2000, with the millennium development goals (MDGs), SD gained further relevance. The MDGs were focused only on a state level (ElAlfy and Weber 2019) and, in addition, only toward developing countries (Caprani 2016). These aspects provoked dissatisfaction among scholars. The MDGs were set to last 15 years and, at the achievement of its maturity, were replaced with the introduction of the 17 sustainable development goals, approved by the United Nations in 2015, which paved the way for a new stage of $\mathrm{SD}$, as these objectives "are integrated and indivisible and balance the three dimensions of sustainable development: the economic, social and environmental" (UN 2015, p. 1). The introduction of the 17 goals, with 169 targets and 232 indicators, emerged after one of the most extensive public consultations that included stakeholders from around 200 countries (Hajer et al. 2015). The publication of the SDGs can be seen as an advancement of the previous MDGs, which can guide governments, corporations, and societies toward achieving long-lasting prosperity (Hajer et al. 2015). The SDGs "[ . . . ] seek to build on the Millennium Development Goals and complete what they did not achieve. [ ... ] seek to realize the human rights of all and to achieve gender equality and the empowerment of all women and girls. [... ] are integrated and indivisible and balance the three dimensions of sustainable development: the economic, social and environmental" and to " ... free the human race from the tyranny of poverty and want and to heal and secure our planet" (UN 2015, p. 1). Weber (2017) criticized the SDGs, as the author considers the goals a result of a political project developed by entities that will most benefit from it, and given the indivisible character of the goals, the agenda may not be realized. Scholars have started to investigate how organizations are contributing to the achievement of the goals through several studies focused on different countries: Italy (Di Vaio and Varriale 2020; Izzo et al. 2020), Spain (Ferro et al. 2019; Mattera and Alba Ruiz-Morales 2021; Peña-Sánchez et al. 2020; Mattera et al. 2021; Diaz-Sarachaga 2021), Greece (Tsalis et al. 2020), Russia (Blagov and Petrova-Savchenko 2021), Japan (Ike et al. 2021), Portugal (Santos and Silva Bastos 2020), India (Poddar et al. 2019), and the Czech Republic and Poland (Šebestová and Sroka 2020). In the case of HEIs, scholars have been investigating different disclosure practices or have focused mainly on intellectual capital disclosure (Fazlagic 2005; Ndou et al. 2018; Brusca et al. 2020; Nicolò et al. 2020; Aversano et al. 2020; Nicolò et al. 2021b).

\subsection{Sustainable Development Goals and Higher Education Institutions}

To this extent, Gamage and Sciulli (Gamage and Sciulli 2017) investigated Australian universities' disclosure by analyzing stand-alone SR. Their study demonstrated a limited number of HEIs issuing SR, a clear inclusion of sustainability issues in the report's vision, strategy, and leadership.

Additionally, Gamage and Sciulli (2017) outline a strong focus on environmental issues and less attention toward other dimensions. Furthermore, in Canada, Sassen and Azizi (2018) outlined an early stage of reporting but a clear commitment toward SR. In addition, the results outlined a commitment toward specific stakeholders, students, and researchers rather than a wider audience (Sassen and Azizi 2018). Furthermore, Nicolò et al. (2021b) explored online sustainability disclosure in Italian universities, demonstrating most universities' clear commitment toward sustainability disclosure. In light of the COVID-19 pandemic, authors outline a significant commitment toward the social dimension rather than the environmental, and in a similar attempt, universities are communicating toward stakeholders how they intend to guarantee the continuity of the universities mission (Nicolò et al. 2021b). Despite the growing body of literature surrounding the SDGs, few 
contributions investigate the role of HEIs in enhancing the goals. Accordingly, it has to be considered that education is an essential key element on which the SDGs are built, and consequently, HEIs represent a significant player that can lead to the achievement of the 17 SDGs. Under this perspective, the sustainable development solutions network (SDSN 2017) considers a wide range of benefits HEIs can obtain by engaging with the SDGs, as the engagement will pinpoint such institutions' relevance worldwide. Furthermore, through the education of future generations, HEIs can prepare future generations with the necessary knowledge and awareness toward the SDGs. Therefore, the implication of HEIs, in each of the SDGs, is essential in informing and mobilizing people through educational strategies and green projects (e.g., campus greening, sustainability research program) toward the SD issue (Leal Filho 2011).

The commitment toward more SD, in the case of HEIs, has been a clear trend in recent years. Since the 1970s, concern for the environment and SD emerged in HEIs, and in recent decades, HEIs have been greening their curriculum and research (Waas et al. 2010), applying environmental management tools (e.g., ISO 14001), or exploring the adoption as well as the extent of sustainability practices and reporting (Ceulemans et al. 2015; Sedlacek 2013; Brusca et al. 2018; Puertas and Marti 2019; Larrán et al. 2018).

HEIs are considered role models in societies (Sedlacek 2013) and sources of new knowledge development through education and research (Deaconu and Nistor 2017). In addition, HEIs are expected to deliver regional economic development in cooperation with local and regional players (Dabija et al. 2017).

While many HEIs demonstrate their commitment toward SD, few institutions report their stakeholders (Ceulemans et al. 2015). In this sense, Radford (2010) argues that the lack of compulsory regulation can represent an obstacle in reaching sustainability in HEIs. However, the low confidence is expressed by Radford (2010). Other scholars outline that the leading countries where HEIs are actively involved in sustainability issues are the United States and the United Kingdom (Puertas and Marti 2019). Furthermore, sustainability practices were already present in France, even before 2009, when SD reporting became mandatory. Thus, despite the lack of compulsory regulation of HEIs' sustainability disclosure, current voluntary reporting practices can play a pivotal role in sustaining HEIs's road to SD disclosure (Chatelain-Ponroy and Morin-Delerm 2016).

Despite the growing expectancies surrounding HEIs, acknowledging the contribution toward the SDGs is still at its beginning, and consequently, scientific contributions are still scant. A case study on a Spanish HEI outlines several difficulties and challenges observed in implementing the SDGs by the HEI and inconsistencies (Albareda-Tiana et al. 2018). In this vein, Sedlacek (2013) explored how HEIs can serve as a relationship booster with other organizations, such as governments and private organizations, to foster sustainable regional development. Through a case study analysis, the author focused on an HEI that has included the principle of sustainable development in its vision and mission and found that the institutionalization of research in SD "is an essential prerequisite for providing successful and effective solutions" (Sedlacek 2013) (p. 83). By adopting the same methodology, Brusca et al. (2018) explored a Spanish HEI's reports and further explored sustainability practices through interviews. Their study demonstrates that the decision motivating the engagement toward the sustainability issue and, consequently, the adoption of sustainability reporting, is related to the intention of the university to increase its legitimacy, reputation, and improve stakeholder engagement (Owens 2017). Brusca et al. (2018) demonstrate the pivotal role of stakeholders in motivating organizational changes.

With the extent to measure HEIs' commitment toward SD, (Puertas and Marti 2019) grounded their study on the UI GreenMetric and developed a ranking based on the efficiency of sustainable development practices. In their ranking, HEIs were divided into four groups according to SD scores. Romanian HEIs, included obtained scores that granted the inclusion of two institutions in the "Medium-Low Group" and one in the "Low Group" (Puertas and Marti 2019), so it can be argued that the path for Romanian HEIs toward a higher SD contribution is still long and requires further investigations. Thus, the changes 
in the program of universities by including in the educational offer of several SD courses (Mustaţă et al. 2013) can have a positive impact on the employability of students (ChatelainPonroy and Morin-Delerm 2016), showing a clear orientation towards sustainability in part of the university, as well as explicit attention to civil society (Dabija et al. 2017). From a similar perspective, Sepetis et al. (Albareda-Tiana et al. 2018), by analyzing the Greek's educational landscape, consider that further inclusion of sustainability issues is crucial for the development of today's students and tomorrow's business owners.

Similarly, Ambrosio Avelar et al. (2019) demonstrate through a literature review the crucial role HEIs hold in achieving the 4th SDG and the relevance of such institutions in educating future generations. Accordingly, Aleixo et al. (2020) demonstrate that undergraduate and master's degrees in Portugal addressed at least one goal in 198 courses on a total sample of 2556 courses analyzed. While many scholars argue about the need and the relevance to further include sustainability subjects in university curricula, Leal Filho et al. (2017) observed different barriers to the implementation of SD in HEIs, such as lack of support from management, appropriate technology, awareness, and concern, environmental committee, buildings with sustainable performance, and government barriers. Furthermore, De la Poza et al. (2021) investigated the SDGs disclosure by HEIs included in the Times Higher Education ranking. Their results demonstrate that most universities did not publish all SDGs; few organizations mention their contribution toward the goals. While the results provided by De la Poza et al. (2021) represent an initial milestone for research related to SDGs and HEIs, the investigation does not explore whether any of the analyzed organizations are paving their way to adopting the goals.

Furthermore, the most disclosed goals were: $3 \mathrm{rd}$, 4th, 5th, 9th, and 17th. In addition, the authors observed an increase of 54\% disclosure toward the goals from 2019 to 2020. Franco et al. (2019) explored how HEIs contributed toward the SDGs and demonstrated a different approach toward the goals per each continent. In addition, it is lacking in the literature, and further studies investigating how HEIs contribute to the goals in terms of policies, curriculum, and practices are required. Finally, in an Italian university, Paletta et al. (Paletta et al. 2020) outline the inclusion of the SDGs in the strategies of Bologna University. To this extent, the authors argue that, through the second edition of the Report, the disclosure tool becomes a vehicle to inform external stakeholders and informative for internal use. In exploring the inclusion of SDGs, Paletta et al. (2020) recognize the need to investigate all stakeholders' participation in changes prompted by the emergence of SDGs.

Furthermore, Mawonde and Togo (2019) explored the case of a South African university and how it has incorporated SDGs in its operations. The analysis unveiled several practices that align the activity of the university toward the goals. Additionally, the authors recognize that the initiative taken by the university is at a small scale. Despite the novelty of the SDGs, few studies are addressing the application of SDGs in HEIs, and further research is required to understand the pathways that enable HEIs to embed SDGs in their strategies. In addition, the existing literature focuses more on a period of one year. It investigates stand-alone reports (sustainability reports or corporate social responsibility reports) rather than demonstrating the transition toward adopting the SDGs from a dynamic and processual perspective. The research outlines how the institution has made its transition toward the adoption of the goals step by step.

\subsection{Stakeholder Theory}

HEIs's pivotal role in today's societies implies an engagement and communication with stakeholders, relevant in expressing the value created for communities, known as the HEIs' third mission (Owens 2017). Additionally, an extended pressure on HEIs to develop study programs according to current needs comes from business organizations (Pop et al. 2011). Consequently, the management relationship with a series of actors makes developing a proper accountability strategy essential for HEIs (Paletta et al. 2020). In this vein, the present investigation is grounded on the stakeholder's theory assumption. Given the broad 
range of stakeholders HEIs have, the adopted theory considers that the institution is in the middle of a network of relations with different stakeholders with other interests.

Consequently, the use of the report for communication purposes can be seen as an attempt to manage and satisfy stakeholders' expectations (Owens 2017). Accordingly, stakeholder theory permits the analysis of the relationship between the organizations, in this case, an HEI, and its stakeholder (Deegan and Blomquist 2006). Freeman (1984) considered the existence of many social contracts between the organization and its stakeholders, which the organization is forced to satisfy. Noteworthy is the different expectations diverse stakeholders can have toward a specific organization (Jongbloed et al. 2008; Nicolò et al. 2019). To this extent, scholars considered that HEIs have to develop their activities in accordance with different stakeholders' demands (Sassen and Azizi 2018; Nicolò et al. 2019). Stakeholder theory outlines to executives how relationships with stakeholders work and how to efficiently manage and shape such relations (Pop et al. 2011). Accordingly, stakeholder theory pinpoints the relevance of voluntary disclosure in improving "organizations' reputations (Oliveira et al. 2013). In the case of the present study, stakeholder theory is used to understand the actions undertaken by the investigated organizations at a social level. It helps to explain the conditions under which such actions have been taken. Stakeholder theory can contribute to the present study, as it can demonstrate how specific activities or programs are directly directed to attract the attention of specific stakeholders" segments or legitimize the university in front of particular social expectations. Due to the increasing relevance of the SD, multiple stakeholders have shifted their expectations toward HEIs, as these are seen as a driver of development (Wakkee et al. 2019) and therefore are driving the change indirectly inside the university. Accordingly, in the case of the BBU, we identified four macro-groups of stakeholders that strongly influence the organization.

Figure 1, represent the stakeholder map has at the center BBU, as it aims to show the central role of the organization in the transition toward SD. Stakeholders are surrounding the organizations, as these are the ones expecting changes and improvements from the investigated organizations, which shall drive the shift toward more sustainable development. Thus, each set of stakeholders, with its expectations, shapes the organizations' behavior (Freeman 1984) and the sets of actions undertaken by the organization to satisfy their demands (Oliveira et al. 2013).

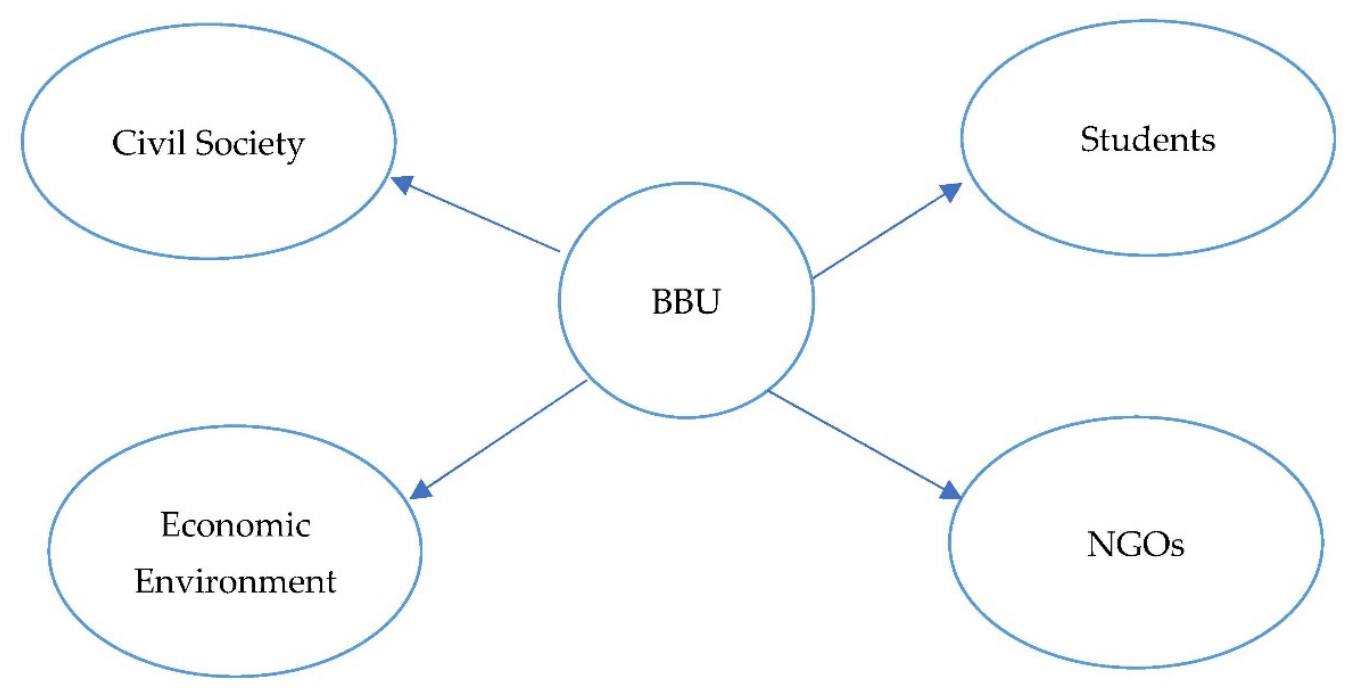

Figure 1. Relevant Stakeholders for SDGs transition.

In the provided stakeholder map, each category is explained below:

(a) Civil Society: community groups, citizens, professional associations, and other groups that might be interested or are affected by the organization's activity;

(b) Students: students currently enrolled in the university, as well as former and potential students; 
(c) Economic environment: all for-profit organizations (private, public, hybrid) interested in the HEI's activity (e.g., educational activities, research activities);

(d) NGOs: all non-governmental organizations that are developing under the HEI's umbrella, which are partnering with the university for different purposes (e.g., research, charitable activities).

\section{Methodology}

The present research aims to explore the sustainability practices developed by BBU. To achieve the research purpose, the present contribution is grounded on the case study methodology developed by Yin (2017). The adopted method allows one to understand a current phenomenon using multiple sources (Sedlacek 2013). The case study methodology is largely adopted in the literature (Sedlacek 2013; Brusca et al. 2018; Albareda-Tiana et al. 2018), as it is particularly suitable when investigating a single organization's behavior on a given phenomenon.

Considering the multiple expectations surrounding universities and previous results that outline a low commitment toward SD issues (Puertas and Marti 2019), the paper presents an in-depth investigation of BBU sustainability practices emergence of SDGs. Furthermore, by exploring the case of BBU, the best Romanian university, which, starting with 2019, joined the UN's SDNS (Sustainable Development Solutions Networks), being the single Romanian member, this study explores the journey of BBU's engagement with the SDG and sustainable universities principles following the SDSN Australia/Pacific (SDSN 2017) guide concerning the SDGs in universities.

\section{a. The Case of Babes-Bolyai University}

BBU is the largest Romanian university and a constant performer in national and international academic rankings. BBU in figures: over 40,000 students enrolled, with a percentage of 24.6 students per teacher, a ratio of 64 females to 34 males (The World University Rankings 2020). It offers study programs in Romanian, Hungarian, German, English, and French. Being a multicultural university, BBU offers a complex of programs in various fields of study. BBU is a complex structure consisting of 21 faculties, 61 research centers, institutes, and laboratories, 18 cultural centers and institutes, human resources, and training centers, a botanical garden, a sports complex, the largest network of academic extensions in the country (13 locations), as well as an impressive network of campuses in Cluj-Napoca, two conference complexes, a cultural heritage department, administrative and technical departments, with a total of 2950 employees (BBU Rector's Annual Report 2018).

BBU was also one of the seven Romanian universities in the Higher Education Universities Rankings by Times Higher Education (THE) in 2019. The ranking classifies universities according to performance indicators grouped into five areas: teaching (teaching, environment, and learning); research (volume, income, and reputation); citations (research influence); international perspectives (staff, students, and research); and the income from the service (knowledge transfer), and the BBU is first place among the Romanian universities. Internationally, it is ranked 166th out of 442 universities analyzed, and the following Romanian university ranked 196th.

According to the meta-ranking of the Romanian universities 2016-2019 (David et al. 2017), BBU is ranked first every year, being recognized at a national level, as a research and education university advanced by the Ministry of National Education. Furthermore, in this meta-ranking, Romanian universities were ranked according to the combined results of their performances from the international academic rankings of the universities.

$\mathrm{BBU}$ is a modern university that deals with developing knowledge, respectively, the transmission of knowledge through education, the generation of knowledge through research, the dissemination of knowledge through education (teaching/learning), and the use of knowledge for services to society. Education is the crucial element in a university, because it differentiates universities from other research units (for example, research institutes) and from those that provide services to society (for example, companies) (Secundo et al. 2021). 
Furthermore, the analysis of one of the largest Eastern European organizations is motivated by the reasons mentioned above and can be used as an example by other eastern European HEIs considering to embark on the SD journey.

\section{b. Data Collection and Data Analysis}

To pursue the research objective, the documents analyzed were those available from the BBU website and are presented in Table 1.

Table 1. Analyzed Documents.

\begin{tabular}{|c|c|}
\hline Year & Document \\
\hline 2016 & BBU Goes green \\
\hline 2016 & $\begin{array}{l}\text { BBU Administrative Council Decision concerning the financial } \\
\text { support for research projects }\end{array}$ \\
\hline 2018 & BBU Sustainable development report \\
\hline 2019 & $\begin{array}{l}\text { BBU Administrative Council Decision concerning the } 2018 \text { BBU } \\
\text { Sustainable development report }\end{array}$ \\
\hline 2016-2017-2018-2019 & BBU Operational plan for 2016, 2017, 2018, 2019 \\
\hline 2016-2019 & Annual BBU Rector's report \\
\hline
\end{tabular}

In addition, we analyzed the following documents:

1. BBU Faculty of Environmental Science and Engineering presentation outlet; BBU Strategic Plan for the period 2016-2020;

2. BBU Administrative Council Decision concerning the Biodiversity and Sustainable Development committee.

Furthermore, we investigate official websites of faculties and research centers with activities related to sustainable development issues. Both authors have studied the documents to explore the different approaches toward SD included in the documents. All the analyzed documents were analyzed by both authors at the same moment and discussed in other sessions to assess BBU's entire road map and whether a particular initiative could fit in the different stages.

The present study analyzes the adoption of SDGs by BBU from a documentary perspective without using interviews to explore the road that led the institution. The documentary analysis was adopted, as all the information was published in a wide range of documents that covered all the motivation and explanations related to changes and plans-interviews that could have been used to promote the HEIs. However, developing a picture that captures the BBU's route toward the implementation of SDGs by using only official documents may shape a subjective image of the case, in the sense that official documents can illustrate what the institutions want stakeholders to see rather than a complete picture of the sustainability behavior of the university. Therefore, to avoid such a pitfall, the present investigation also explores how the BBU posits itself, through its sustainable actions, in international rankings related to sustainable development issues. Given the impartial character global rankings have, the present research adopted the following ranks: University Impact Rankings 2019, which considers how universities contribute broadly to the SDGs, and UI GreenMetricWorld University Ranking, which assumes the levels of sustainability in HEIs.

Using the internationally recognized SDSN framework, this paper analyses the sustainability practices of one of the most famous Romanian HEIs. SDSN is part of the United Nations network. Its main objective is to support the SDGs' implementation by creating a global network of universities, research centers, and other knowledge institutions to convert expertise in sustainable development into reality. Even if it was established in 2012, it already enumerates 682 universities and 127 research institutes. Furthermore, the 
SDSN (2017) pinpoint a set of five main characteristics for recognizing the degree to which organizations are orienting toward the SDGs, and these are:

1. Mapping what they are already doing

2. Building internal capacity and ownership of the SDGs

3. Identifying priorities, opportunities, and gaps

4. Integrating, implementing, and embedding the SDGs within university strategies, policies, and plans

5. Monitoring, evaluating, and communicating their actions on the SDGs.

These might be grouped into three significant stages on an HEI engagement with SDGs:

A. Recognition: Identifying and acknowledging what a university is already doing to contribute to the SDGs can provide a powerful narrative about the impact and a strong impetus for further action (1).

B. Opportunistic: Different areas across the university recognize the usefulness and importance of the SDG framework and find opportunities to use it to the frame or drive discrete activities and programs without an overall strategy (2 and 3).

C. Organizational: The ongoing and far-reaching impact will come if the SDGs become part of the current activity for the HEIs, by recognizing/integrating the SDG framework into all relevant university governance structures and frameworks (4 and 5).

Depending on their context and starting point, there is a high degree of flexibility in addressing these characteristics and stages, and there is no standardized way for universities to implement or support SDGs. There are significant differences between universities from different points of view, including size, structure, access to funding, existing progress in sustainable development, values, priorities, and needs of the communities they serve. The information collected from the official documents issued by the BBU and the data collected from the international rankings and the BBU's policies on SD were analyzed through a qualitative interpretative approach (Corbin and Strauss 1990). Accordingly, documents were analyzed and interpreted to extract information relevant to the research aim.

To construct validity, the investigation adopts a similar approach to Secundo et al. (Secundo et al. 2021). The construct validity has been assured by analyzing multiple official documents (see Table 1). In combination with the analysis of official websites, the official documents contribute to the trustworthiness of the exposed data. The internal validity is assured by exploring actual actions taken after the issuance of the reports. External validity is generated through the generalization of the results (Secundo et al. 2021). In this vein, the results can be compared to other or similar studies. The replicability of the research is assured through the archived documents accessible by other researchers, which generates reliability. The present research is part of the qualitative research flow, through the analysis of papers performed, especially suitable for exploring extreme cases that draw a loaded portrait of a single phenomenon (Yin 2017). This technique is widely adopted in studies on providing information, quality, and compliance of reports.

Moreover, this research method is particularly appropriate, as the study explores the extent to which a series of information is provided without following an existing framework. In this order of ideas, by combining a series of documents, the methodology adopted can guide the authors in constructing the course of the investigated institution to implement the SDG. The data collected were combined with the authors' participatory observations, who took part in a series of discussion groups, meetings (for example, BBU working groups), and European working groups and research networks. The combination of official documents and observations helps the authors to find practical convergence and corroboration to meet the research objective (Eisner 2017). The stages mentioned above support the research effort in demonstrating that the results are not a production of a single methodology, sources, or inclinations. Given the above statements, the results were further organized according to the framework presented in the research design. 


\section{Results and Discussion}

Analyzing the BBU case through the lens of the SNSD framework, the historical evolution of policies and initiatives, reveals that the SD focus in BBU emerged through the following journey presented in Table 2:

Table 2. Stages of the BBU and SD Actions.

\begin{tabular}{cccc}
\hline Period & Stage & Actions with a Specific Emphasis on SDGs & Universities' Missions \\
\hline $\begin{array}{c}\text { before 2016 } \\
\text { 2016-2018 }\end{array}$ & Opportunistic & $\begin{array}{c}\text { New educational programs, Formal or } \\
\text { informal research groups from the same or } \\
\text { different domains, Articles published on } \\
\text { different SDG issues }\end{array}$ & $\begin{array}{c}\text { Teaching, Research } \\
\text { 2016-2018 }\end{array}$ \\
$\begin{array}{c}\text { Organizational } \\
\text { 2018-present } \\
\text { Period } \\
\text { before 2016 }\end{array}$ & $\begin{array}{c}\text { SD Strategy, Action, and Strategic Annual } \\
\text { Plan, Faculties strategies, Follow-up plans, } \\
\text { improvements, }\end{array}$ & Transfer, Research \\
\hline Recognition & $\begin{array}{c}\text { Rector Annual Report, BBU Sustainable } \\
\text { dissemination actions, young generation } \\
\text { involvement }\end{array}$ & Teaching, Research, Transfer \\
\hline
\end{tabular}

\subsection{Opportunistic Stage}

BBU has assumed, through the strategic plan for the period 2016-2020, an unchanging role of academic institutions, with priorities subscribed to the idea of continuity, competitiveness, and excellence. BBU continues to assume a responsible and active role to provide competent graduate companies trained in a university environment characterized by an orientation toward knowledge, innovation, and cooperation with the business environment (Franco et al. 2019). In this context, different faculties and communities of the BBU recognize the relevance of SD. Thus, faculties in the field of environment, geography, chemistry, and economics started before 2016 to identify the priorities and opportunities for education and research of different aspects of SD and the gaps in their education programs and began to consolidate their internal capacity and ownership of SDGs. Through these faculties, BBU provides students with the knowledge, skills, and motivation to understand and address the challenges of SDGs, as already observed in the literature (Owens 2017; Mustaţă et al. 2013).

Furthermore, faculties started to contribute toward SD by developing several specializations: environmental engineer, conservation specialist, inspector specialized in water management, specialists in the management and remediation of contaminated sites, a specialist in protected areas, and specialist in waste management. The Faculty of Environmental Sciences and Engineering (FESE) is dedicated directly to sustainability issues and is one of the most dynamic faculties of the BBU. It offers training in environmental issues-at bachelor's, master's and doctoral levels-in the newest, most attractive, and most sought after specializations-environmental science (in Romanian and Hungarian), environmental geography, environmental engineering, biotechnical and ecological systems engineering (license), risk assessment and environmental safety, environmental management and protection, environmental quality and energy sources, engineering for waste recovery and sustainable development, and environmental management. Given these elements, it can be stated that BBU educates future generations toward SD (Sedlacek 2013). Over the years, the faculties have continuously developed and adapted their priorities promoted in educational policies and environmental strategies while responding to the increasing and demanding demand of the labor market (Pop et al. 2011; Bratianu and Vatamanescu 2017). Moreover, BBU offers consultancy in this area.

Additionally, during this period, before 2016, in different research centers with themes in the SD area (e.g., the Institute for Disaster Management and the Research Centre for Sustainable Development), BBU have entered the international research networks, as 
well as international and national research projects in the SD area. Currently, activities continue at a higher level, with BBU being involved in international research projects of great importance (e.g., on ecological fuels, the CONVERGE-CarbON Valorisation in Energy-efficient Green Fuels project, 2018-2022).

At the institutional level, within the Strategic Plan of the BBU for 2016-2020, the management and support activities have a strategic objective: to optimize maintenance costs and identify renewable energy resources with the following purposes and indicators. 1. They are reducing the buildings' maintenance costs (degree of reduction in maintenance costs) (civil society). 2. Use of renewable energy sources (the number of renewable energy sources used) (civil society). 3. Collecting particular waste to reduce the impact on the environment (quantity of recycled waste) (civil society). 4. Creation of pilot programs on green energy in the BBU (number of programs created) (civil society and students). Accordingly, due to the multitude of problems related to the natural resources hosted by the $\mathrm{BBU}$, a commission for the evaluation of the green spaces of the BBU was established in 2016 (BBU decision 1.344/26.01.2016). Therefore, after the issuance of the sustainability strategy of the BBU, at the end of 2016, the concern of the BBU for sustainable development becomes a continuous process for which a related internal capacity is built and a connection of the BBU's activities with SDGs is ensured, with constant monitoring of priorities, opportunities and identifying gaps.

It can be concluded that the BBU has observed the stakeholders' expectations and met these requirements. Consequently, the institution has modified part of its educational programs (Sassen and Azizi 2018) (students). Although several scholars have argued about the necessity of HEIs to contribute through all possible means to the SDGs (Avelar et al. 2019; Aleixo et al. 2020), the approach adopted by BBU demonstrates a clear commitment toward an education that will contribute to the SD's comprehension of future generations. Furthermore, it is possible to consider the early adoption of SD curricula by BBU as a sign of perception regarding external expectations regarding the curricula thought at the different faculties. In a similar perspective, BBU, through its institutional initiatives, aims to respond to the wide variety of stakeholders that HEIs have. In this stage, the institution has developed early courses oriented to explaining the SD phenomena and its impact. Therefore, BBU's opportunistic scene demonstrates the ' 'university's acknowledgment of different stakeholders HEIs have to face (Brusca et al. 2018; Sassen and Azizi 2018). The current stage outlines similarities with existing studies (Mawonde and Togo 2019; Paletta et al. 2020), although the institution is only at the beginning of its path on SDGs contribution.

Furthermore, the primary stage confirms the results provided by De la Poza et al. (2021), as at the current stage, the institution has a mere approach toward the SDGs and acknowledges only a few of the goals. Different stakeholders motivated the institution to undergo such a path in the current stage: students and civil society. Therefore, it can be seen that the plans developed by the institution are oriented to satisfy stakeholders' expectations about SD (Oliveira et al. 2013; Brusca et al. 2018).

\subsection{Organizational Stage}

Even though before 2016, faculties were offering educational programs and formal or informal groups of researchers interested in sustainable development, BBU's commitment to sustainable development was formalized (students, NGOs, and civil society). It became official in 2016, when BBU issued the Sustainable Development Program (BBU decision no. 21036/31.10.2019). Through this strategy, BBU aims to ensure sustainable development, protect the environment and nature, and underline its commitment to reduce the ecological footprint of BBU. Thus, for BBU, as in Spanish universities, sustainability is part of its fundamental values (Owens 2017). The strategy follows national, European, and international regulations, recommendations, and trends regarding sustainable development (e.g., Romania's National Strategy for Sustainable Development, Horizon 2013-2020-2030, the European Union, and the United Nations). From this moment, SD becomes part of the 
"current activity" for the BBU by recognizing and integrating the OSD framework in all relevant university governance structures and frameworks, as described by SDSN (2017). Entitled BBU Goes Green, the sustainable development strategy of BBU states that:

"The University is taking concrete steps towards the implementation of energy (both electricity and gas) and the water conservation program, a waste management program (including recycling, but also the handling of toxic waste, composting and used electrical equipment), a transport policy, together with an ecological education program. The program aims to mainly involve university students; on the one hand, to raise awareness of ecological issues, while on the other, to support the activities and events initiated by students that address sustainability".

The program is meant to involve BBU in the broader international movement related to SD and implement policies that reduce the anthropic impact on the environment (BBU Rector's Annual Report 2018). The BBU Goes Green program is a general reference and development framework for BBU's academic and administrative activities and is coordinated by the STAR-BBU Institute. The strategy contains a plan with the following minimum measures:

"(1) Ensuring the functioning of the green.BBUcluj.ro web page.

(2) a "green" button in the BBU Academic Activity Management application will allow ticking of activities (at least publications and conferences) that are related to SD.

(3) Adoption at the administrative level of the resources of the use policy, reducing the ecological footprint of the $B B U$ and its academic community regarding the status of lighting, the use of electricity, thermal installations, water, as well as at the level of waste management (non-toxic and toxic), parking, transport, and buildings,

(4) SD education to raise awareness of sustainability issues and, on the other hand, to support activities and events initiated by students addressing ecological issues". (BBU Rector's Annual Report 2018)

With the same intent, the Commission for Sustainable Development and Biodiversity was set up in 2018 (CSDB) (Decision BBU 21832 of 26 November 2018) by renaming the former Commission for Green Spaces of 2016. CSDB members are specialists in SD from academic and non-academic staff. They have a role in analyzing the state of natural resources from the administration of BBU and elaborate strategic documents regarding the modalities of their protection, but also measures of ecological education leading to the awareness of the importance of their preservation. By the end of each calendar year, BSDC prepares the BBU Sustainability Report, which presents the degree of achievement of the objectives included in the BBU program goes green. Moreover, to promote the culture of social inclusion and non-discriminatory policies, the BBU has developed a guide to combating discrimination (BBU Decision No. 10480/06.06.2018).

The policy of SD of the BBU was taken over and adopted by the faculties (for example, Chemistry and Faculty of Economic Science and Business Administration) (students, NGOs, civil society, economic environment). With points, for example, in the case of Chemistry, which refers to:

1. Regular campaigns in collaboration with student organizations for waste recovery

2. Management of chemical substances and waste according to the norms in force

3. New SD courses: green chemistry, hazardous waste management, industrial pollutants

4. A research project on clean energy, biotechnologies, biomaterials,

5. All equipment and computers are turned off and removed when not in use.

In this case, the courses developed and the campaigns in combination with student organizations demonstrate how the institution is shaping in a direct and indirect manner the behavior of future entrepreneur generations who will be more aware of waste management and environmental regulation. The inclusion of SD issues in activities and courses emerges only after the first stage (opportunistic), as in the primary phase, the need for 
such activities is perceived by the organization. In the current set (organizational), the institution demonstrates direct actions taken to answer stakeholder expectations.

Additionally, BBU has developed research directions and projects on the topic of SD within several faculties. These programs address a wide range of issues related to sustainable development, carbon dioxide emissions, alternative energy sources, unconventional materials, disaster management, the landscape of sustainable development, the conservation of specific endangered populations, climate change, and their effects. Moreover, in internal evaluations, projects with a sustainability component receive a better evaluation. During the 2016-2018 period, the institutional framework of SD of the BBU was created. After 2018, the organizational stage continued on the level of improvement.

Some of the tools used to measure and evaluate BBU SD commitments were already in place at the university before 2018. For example, in the rector's annual report for 2016, 2017 , and 2018, there are references to some SDGs, but not directly referring to the existing diversity and inclusion, gender relations, and other similar aspects. Issues related to the SDG, still without an explicit mention, were also requested to be reported to the Ministry of Education, funding agencies, and international networks in which the BBU is a member. In addition, each annual report of the BBU for the period after 2016 includes references to the BBU's contribution to the different SDGs. The reports present the main contribution areas considered by the BBU: learning and teaching, research, organizational governance, culture, and university operations with the community. BBU's commitment to SDGs is visible in the rector's annual reports for 2016, 2017, and 2018, where there are references to the program "BBU goes green" as a goal in 2016 and its implementation.

In conclusion, we affirm that BBU has identified the best way to integrate and implement the commitment and actions on SDGs to ensure that BBU is leading the way and can become a champion for SD, at least at a national level. SDGs are included in various government vehicles, establishing mechanisms to coordinate BBU actions on SDGs and implementing policies, strategies, and/or action plans. To this end, the management of BBU has made clear and widely supported decisions on how SDGs will be integrated into all key university strategies and policies. These strategies and policies include the strategic plan of the BBU, the research framework, the learning and teaching framework, and others. In addition, BBU's commitment and actions on SDGs are reflected in the BBU's sustainable development policy, which governs the university's approach to SD.

In conclusion, BBU involvement in SD is essential in informing and mobilizing people through educational strategies (Leal Filho 2011), environmental projects, and the adoption of sustainable practices (Sedlacek 2013; Ceulemans et al. 2015; Dabija et al. 2017; Brusca et al. 2018; Larrán et al. 2018; Puertas and Marti 2019). Furthermore, the organizational stage brings additional recognition toward the SDGs, which outlines the evolution of the contribution by the institution, which goes beyond the mere acknowledgment of a few of the goals (De la Poza et al. 2021). Additionally, the summarized results contribute to the literature as it demonstrates which actions the institution takes to contribute to the plans. Such observations are still scant in the literature (Franco et al. 2019). Moreover, the results outline a higher inclusion in curricula compared to the results provided by Ambrosio Avelar et al. (2019). In the case of the current, stage multiple stakeholders are involved in the changes taken by BBU. As stated previously, students and civil society are at the center of the change, although it can be considered that NGOs are also at the center of the institutions' change. Accordingly, multiple stakeholders were expecting changes, and the institution has addressed such parts through a larger contribution toward the goals.

\subsection{Recognition Stage}

Identifying and recognizing what BBU is already doing to the SDGs offers a strong narrative about the impact and impetus for further action. BBU issued for the first time in 2019 a voluntary report dedicated to SD. The BBU Sustainability Report 2018, with 22 pages, contains an introductory part explaining the national and international context of the universities' commitments to SDGs. A consistent part is dedicated to the BBU 
context with academic programs, directions, research programs, scholarship students, accommodation and dining spaces, study facilities, medical and transport social services, cultural services, botanical gardens, and green areas BBU (all stakeholders). In addition, the report covers the contributions of BBU to the SDGs in terms of research and education (curriculum) (students).

In this case, the curriculum has improved compared to the previous stage as more faculties started to provide courses on SD (i.e., faculty of economics), the inclusion of systems-oriented to the teaching of the corporate reporting relevance and consequently shaping future entrepreneurs' conceptions about sustainability. Another part is allocated to the sustainable development strategies and activities within the BBU, including here the BBU Goes Green strategy, the role and activities of the Commission for Biodiversity and Sustainable Development, and the implementation of the sustainable development strategy. The last part of the report includes the strategic purpose and directions of the actions presenting results and indicators, long-term objectives, and the next period's action plan. The report refers to the requirements and priorities imposed at both European and national levels regarding SD policies. This voluntary report also has the role of monitoring, evaluating, and communicating the BBU's actions on the sustainability issues (ChatelainPonroy and Morin-Delerm 2016). Sustainability reporting provides a powerful tool for educational institutions to assess their performance and communicate sustainability efforts to stakeholders and society in general (Ceulemans et al. 2015). BBU adopts voluntary disclosure strategies to meet stakeholder expectations (Oliveira et al. 2013), and these strategies can be seen as an attempt to develop an appropriate accountability strategy (Jongbloed et al. 2008) aimed at the multitude of stakeholders of a higher education institution (Owens 2017).

Starting with 2019, BBU (through the Center for Research for Sustainable Development) is the first university in Romania to be part of the Network for Sustainable Development (NSD), which has been operating since 2012 under the auspices of the UN Secretary General. The network promotes practical solutions for SD. Affiliation also comes as recognition of BBU's strategy and research in the field of SD. BBU is also a member of the Education and Research for Sustainable Development (ERSD) developed by the International Association of Universities (IAU), which provides access to actions and initiatives developed worldwide to promote sustainability. Seven hundred thirty-five universities and 90 organizations are members of this network, working together on all dimensions of SDG.

International rankings give international recognition of BBU's commitment to the impact of SDG. The Times Higher Education University Impact Rankings (THE) is the only ranking that assesses the overall performance of universities following the United Nations SDGs. Following the ranking requirements, a university must provide data on SDG 17 and at least three other SDG to be included in the overall ranking. The first edition was issued in 2019 using HEIs data for 2017. BBU provided data on SDG 17 and SDG 4, 9, 10, and 16 and obtained a total value in the range 53.7-64.5 from the group 201-300 out of 450. BBU received the best position on SDG 16, ranking 37th, and according to each SDG, there is an exception related to SDG 9, BBU being in the second position.

In the UI, GreenMetricBBU is ranked second nationally in the period 2016-2019. A positive evolution is registered regarding the total score (3615 in 2016 to 5350 in 2019 and ranks from 360/516 in 2016 to 316/780 in 2019). This evolution demonstrates a strong commitment, analyzing parameters. The most notable positive growth is found in the water indicator. As part of the BBU Goes Green strategy, BBU has increased efforts to reduce water consumption, increase the conservation program, protect habitat, and use water-efficient appliances (all stakeholders). The infrastructure indicator contains basic information on the BBUs policy towards the green environment and the label of the green campus. Energy and climate change capture the BBU's focus on energy use and climate change (consumption of energy-efficient appliances, policy for using royal energy non-sustainable, mitigation program, and greenhouse gas emission reduction policy). These elements are also included 
in the Goes Green strategy and operational plans. The criterion of education and research refers to courses on sustainability topics, funding of sustainability research, publications on environment and sustainability, academic events related to environment and sustainability, student organizations with activities on environment and sustainability, the existence of a website dedicated to sustainability managed by the university, and not least, the published sustainability report. According to the stakeholder theory objective, it is possible to consider that the results and the increasing commitment to SD make it possible to observe a dissemination attempt made by the BBU.

Dissemination is vital for informing, educating, modeling, and engaging future generations and informing stakeholders (Owens 2017). Now, BBU is in the process of creating cohesive and well-grounded monitoring, evaluation, and communication plan that will allow BBU to create and share compelling "stories" to attract both the support needed for their future engagement with SDG and for to broaden the common understanding of the SDG. The SD activities of the BBU were broadcast on the BBU website and radio and disseminated in the media using formal and informal communication channels, issuing press releases on the theme of each event, action, and campaign (pre- and post-event), including publication of information regarding the campaigns organized on the BBU website and the social networks and plasmas in the BBU Rectorate; making posters to promote events; and making leaflets/presentation brochures.

In particular, the engagement of young people is essential for the BBU, and in this sense, the BBU has started to organize workshops and seminars for the BBU students and high school students on DS topics directly involving the student organizations. For example, BBU mobilizes young people through the annual "Keep It Green" and "Keep it Clean and Green!" events; planting and cleaning trees in the Sports Park, involving over 300 high school students, BBU students, and academic and technical staff; or CSR and blood donation campaigns.

Thus, BBU develops its SD activities considering the requirements of different stakeholders (Sassen and Azizi 2018) and capitalizes on the importance of relationships with stakeholders. Therefore, within the stakeholder theory, we can conclude that BBU emphasizes relationships with stakeholders. Moreover, by issuing a voluntary sustainability report, the reputation of the BBU could increase (Oliveira et al. 2013). The final stage covers all the exposed stakeholders in Figure 2. The current stage demonstrates how the institution plans to work and contribute to SD, including business organizations. BBU's effort to communicate to stakeholders its commitment and contribution toward the SDGs is corroborated by the inclusion of the university in relevant international rankings that recognize the actual contribution of the institution. In this vein, stakeholders' expectations (Freeman 1984; Nicolò et al. 2019) are met through reports and other communication tools and membership in international rankings.

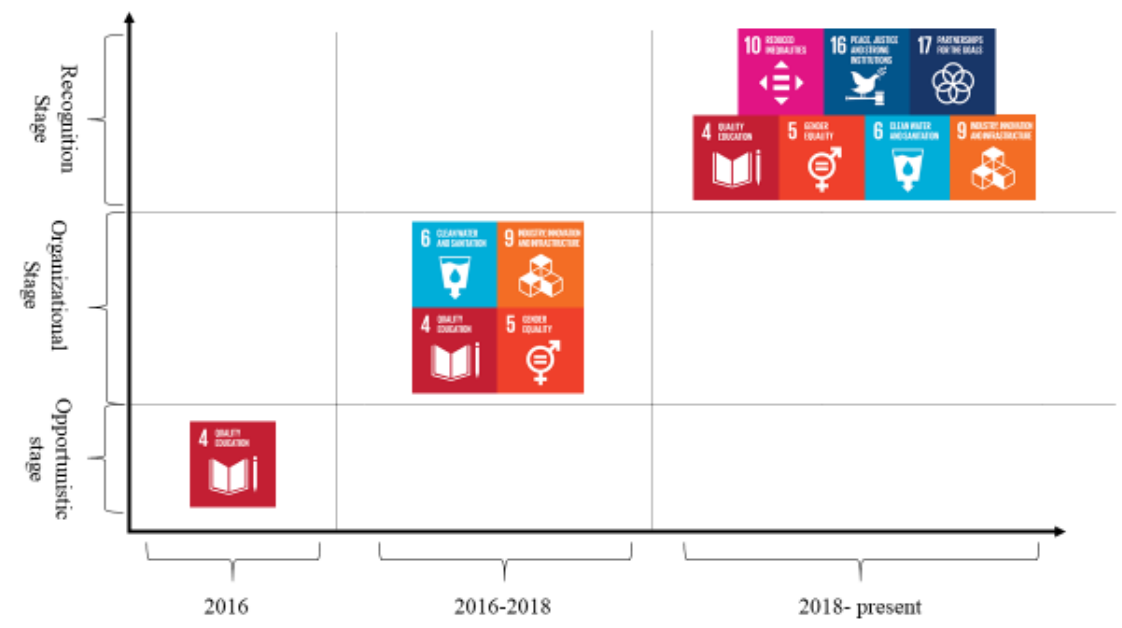

Figure 2. BBU's Contribution toward the SDGs. 


\section{Conclusions}

The present paper aimed to investigate how BBU has contributed to the SDGs in the latest years. BBU's journey has demonstrated a continuous progression toward a contribution toward different SDGs. Indeed, BBU's path is not over as the university contributes to 7 out of the 17 Goals, but the data extracted from official documents provide a solid foundation for a more extensive adoption and contribution toward the UN SDGs.

BBU's journey observed the need to further enrich the academic curriculum toward SD issues (Sassen and Azizi 2018; Avelar et al. 2019; Sepetis et al. 2020) and took action to answer stakeholders' demands (Freeman 1984; Deegan and Blomquist 2006). In this case, BBU, in its opportunistic stage, began its contribution toward the fourth goal, demonstrating a clear understanding of stakeholders' needs. The opportunistic stage paved the way for a greater acknowledgment of BBU's contribution toward the goals. In this sense, the institution opened its horizon in the organizational stage and accentuated its contribution toward the goals through several policies. In this stage, it is possible to observe an institutional approach toward the goals, as most activities and policies are developed to introduce a shift toward a more sustainable university to co-operate with a broad range of stakeholders (Freeman 1984). Under a theoretical perspective, it can be noted that the previous stage has contributed mainly to facing the need of those who join courses at BBU, while the current stage outlines an attempt to co-operate with society at large (Jongbloed et al. 2008) and contributes to different goals. The recognition stage represents the final step of our analysis and demonstrates how international rankings have recognized the institution for its contribution toward the Goals. In this perspective, it is possible to observe a defined pathway toward a continuous improvement of the contribution toward the goals over the years. The final stage demonstrates how stakeholders have been increasing their interests toward the contribution of the goals, thus recognizing the institution's activity through international rankings.

Accordingly, the recognition given to the institution represents a clear sign toward the multitude of stakeholders that BBU faces and shows how the institution is trying to meet its expectations (Deegan and Blomquist 2006; Sassen and Azizi 2018). In addition, the contribution toward the SDGs does not allow for comparison due to the early stage of the involvement. However, the following figure aims to outline the pathway that leads BBU to contribute to several goals.

The goals included in the figure above are extracted from the institution's activities and connected to the goals and the international rankings that evaluated BBU's policies. Thus, the figure outlines a growing commitment toward the goals. Nevertheless, the commitment is not explicit, and BBU needs to take a further step in acknowledging through an official report that aims to communicate to stakeholders BBU's policies and activities.

Debates on how universities implement sustainability policies are topical, especially as $\mathrm{SD}$ begins to be recognized in international rankings and interested parties request such information. Therefore, the present paper followed how the BBU built its path towards an institutional commitment in adopting a strategy-oriented more towards sustainable development, from a longitudinal perspective, reaching a recognition of its contributions towards achieving the SDG. From this perspective, the investigation adopts a set of three stages to understand how and by what strategies BBU has become a possible benchmark regarding SD for the Romanian universities.

The changes undertaken by the university, in the organizational stage, to become more involved in SD demonstrate a clear intention to satisfy the multiple stakeholders with whom they interact. Finally, the recognition phase underlines the institution's attempt to expose its best practices to stakeholders and form and manage future relationships with stakeholders through a wide variety of activities in which younger generations are at the center. In light of the concepts mentioned above, stakeholder theory demonstrates how the needs of external stakeholders lead to changes in BBU strategies.

The present paper contributes to the specialized literature by offering an example of good practice of a Romanian university. In particular, the current form fills an existing 
gap in the literature (Franco et al. 2019), as it demonstrates, in terms of policies, curricula, and practices, the contribution of the HEI toward the SDGs. Furthermore, the current research covers 2016 to 2019, analyzing the evolving contribution toward the goals. In this perspective, the paper contributes to the literature as it focuses on the issue of SD reporting from universities (Waas et al. 2010) from a longitudinal view (Gamage and Sciulli 2017).

The novelty of the contribution consists of the analysis of an eastern European university, often ignored by the literature. Nevertheless, the case study of one of the largest HEIs in eastern Europe can serve as a trailblazer for other HEIs in the same geographical area. Furthermore, the results can be helpful for political decision-makers, because the methodology used can analyze the degree of involvement of other universities in SD.

From a managerial perspective, the results included in the present investigation outline to BBU 's members its current contribution and how this can improve in the future, and in which area the institution shall have an additional contribution. From an external perspective, the results of the present paper can serve as a model for other Romanian or eastern HEIs that are taken into consideration to begin contributing toward the SDGs as the evidence provided in the paper exemplify the roadmap of an HEIs.

Furthermore, the present paper demonstrates that HEIs can and have to engage in SD practices through all the three missions of universities. In this vein, policymakers shall consider the current paper's results to enhance HEIs' contribution to SD.

Despite the contributions mentioned above, the study has some limitations, as only one university is considered. An additional limitation is the type of sources used for the analysis, as the information was collected mainly from official documents. Therefore, the lack of interviews limits the results, as through the documents, it has been possible to observe only information included in documents and websites, while through interviews, it could have been possible to have a deeper understating of why particular actions were taken.

In this vein, further studies shall consider deepening the present investigation through interviews with university representatives and other stakeholders to explore whether the institution's action is deemed to be sufficient for its role. Furthermore, future research shall include more HEIs in the study either from Romania or other eastern European countries and others. Additionally, a broader exploration of Romanian HEIs' contribution toward the SDGs would be particularly interesting as it will demonstrate the status of SDGs' contribution from a national level.

Author Contributions: All authors contributed equally to the paper. All authors have read and agreed to the published version of the manuscript.

Funding: This work was possible with the financial support of the Operational Programme Human Capital 2014-2020, under the project number POCU 123793 with the title "Researcher, future entrepreneur-New Generation".

Institutional Review Board Statement: Not applicable.

Informed Consent Statement: Not applicable.

Conflicts of Interest: The authors declare no conflict of interest.

\section{References}

Albareda-Tiana, Silvia, Salvador Vidal-Raméntol, and Mónica Fernández-Morilla. 2018. Implementing the sustainable development goals at University level. International Journal of Sustainability in Higher Education 19: 473-97. [CrossRef]

Aleixo, Ana Marta, Ulisses M. Azeiteiro, and Susana Leal. 2020. Are the sustainable development goals being implemented in the Portuguese higher education formative offer? International Journal of Sustainability in Higher Education 21: 336-52. [CrossRef]

Avelar, Aline Bento Ambrosio, Keilla Dayane da Silva-Oliveira, and Raquel da Silva Pereira. 2019. Education for advancing the implementation of the Sustainable Development Goals: A systematic approach. The International Journal of Management Education 17: 100322. [CrossRef]

Aversano, Natalia, Giuseppe Nicolò, Giuseppe Sannino, and Paolo Tartaglia Polcini. 2020. The Integrated Plan in Italian public universities: New patterns in intellectual capital disclosure. Meditari Accountancy Research 28: 655-79. [CrossRef] 
Babes-Boylai University Rector's Annual Report. 2018. Cluj-Napoca. Available online: https://www.ubbcluj.ro/ro/infoubb/ documente_publice/files/raport-rector/Raport_Rector_2018.pdf (accessed on 20 January 2021).

Barkemeyer, Ralf, Diane Holt, Lutz Preuss, and Stephen Tsang. 2014. What happened to the 'development'in sustainable development? Business guidelines two decades after Brundtland. Sustainable Development 22: 15-32. [CrossRef]

Bebbington, Jan. 2001. Sustainable development: A review of the international development, business and accounting literature. Accounting Forum 25: 128-57. [CrossRef]

Blagov, Yury E., and Anastasia A. Petrova-Savchenko. 2021. The transformation of corporate sustainability model in the context of achieving the UN SDGs: Evidence from the leading Russian companies. Corporate Governance 21: 307-21. [CrossRef]

Bratianu, Constantin, and Elena-Madalina Vatamanescu. 2017. Students' perception on developing conceptual generic skills for business: A knowledge-based approach. VINE Journal of Information and Knowledge Management Systems 47: 490-505. [CrossRef]

Brusca, Isabel, Margarita Labrador, and Manuel Larran. 2018. The challenge of sustainability and integrated reporting at universities: A case study. Journal of Cleaner Production 188: 347-54. [CrossRef]

Brusca, Isabel, Sandra Cohen, Francesca Manes-Rossi, and Giuseppe Nicolò. 2020. Intellectual capital disclosure and academic rankings in European universities: Do they go hand in hand? Meditari Accountancy Research 28: 51-71.

Caprani, Lily. 2016. Five ways the sustainable development goals are better than the millennium development goals and why every educationalist should care. Management in Education 30: 102-4. [CrossRef]

Ceulemans, Kim, Ingrid Molderez, and Luc Van Liedekerke. 2015. Sustainability reporting in higher education: A comprehensive review of the recent literature and paths for further research. Journal of Cleaner Production 106: 127-43. [CrossRef]

Chatelain-Ponroy, Stéphanie, and Sophie Morin-Delerm. 2016. Adoption of sustainable development reporting by universities: An analysis of French first-time reporters. Accounting, Auditing \& Accountability Journal 29: 887-918.

Corbin, Juliet M., and Anselm Strauss. 1990. Grounded theory research: Procedures, canons, and evaluative criteria. Qualitative Sociology 13: 3-21. [CrossRef]

Dabija, Dan-Cristian, Catalin Postelnicu, and Nicolae Al Pop. 2014. Methodology for Assesing the Degree of Internationalization of Business Academic Study Programmes. Amfiteatru Economic 16: 37.

Dabija, Dan-Cristian, Cătălin Postelnicu, Vasile Dinu, and Alin Mihăilă. 2017. Stakeholders' perception of sustainability orientation within a major Romanian University. International Journal of Sustainability in Higher Education 18: 533-53. [CrossRef]

David, D., O. Andronesi, C. Buzea, B. Florian, S. Matu, and L. Vlasceanu. 2017. Metaranking Romanian University Ranking. Journal of Research in Higher Education 1: 31-50. [CrossRef]

De la Poza, Elena, Paloma Merello, Antonio Barberá, and Alberto Celani. 2021. Universities' Reporting on SDGs: Using THE Impact Rankings to Model and Measure their Contribution to Sustainability. Sustainability 13: 2038. [CrossRef]

Deaconu, Adela, and Cristina Silvia Nistor. 2017. Competences in Romanian higher education-an empirical investigation for the business sector. Studies in Higher Education 42: 1917-40. [CrossRef]

Deegan, Craig, and Christopher Blomquist. 2006. Stakeholder influence on corporate reporting: An exploration of the interaction between WWF-Australia and the Australian minerals industry. Accounting, Organizations and Society 31: 343-72. [CrossRef]

Di Vaio, Assunta, and Luisa Varriale. 2020. Blockchain technology in supply chain management for sustainable performance: Evidence from the airport industry. International Journal of Information Management 52: 102014. [CrossRef]

Diaz-Sarachaga, Jose Manuel. 2021. Monetizing impacts of Spanish companies toward the Sustainable Development Goals. Corporate Social Responsibility and Environmental Management 28: 1313-23. [CrossRef]

Eisner, Elliot W. 2017. The Enlightened Eye: Qualitative Inquiry and the Enhancement of Educational Practice. New York: Teachers College Press.

ElAlfy, Amr, and Olaf Weber. 2019. Corporate Sustainability Reporting: The Case of the Banking Industry. Kozhikode: CIGI Papers, p. 211.

Fazlagic, Amir. 2005. Measuring the Intellectual Capital of a University. Trabajo Presentado en Trends in the Management of Human Resources in Higher Education. París: Francia.

Ferro, Carlos, Carmen Padin, Nils Høgevold, Göran Svensson, and Juan Carlos Sosa Varela. 2019. Validating and expanding a framework of a triple bottom line dominant logic for business sustainability through time and across contexts. Journal of Business $\mathcal{E}$ Industrial Marketing 34: 95-116.

Franco, Isabel, Osamu Saito, Philip Vaughter, Josh Whereat, Norichika Kanie, and Akio Takemoto. 2019. Higher education for sustainable development: Actioning the global goals in policy, curriculum and practice. Sustainability Science 14: 1621-42. [CrossRef]

Freeman, R. Edward. 1984. Strategic management: A stakeholder theory. Journal of Management Studies 39: 1-21.

Gamage, Pandula, and Nick Sciulli. 2017. Sustainability reporting by Australian universities. Australian Journal of Public Administration 76: 187-203. [CrossRef]

Hajer, Maarten, Måns Nilsson, Kate Raworth, Peter Bakker, Frans Berkhout, Yvo de Boer, Johan Rockström, Kathrin Ludwig, and Marcel Kok. 2015. Beyond cockpit-ism: Four insights to enhance the transformative potential of the sustainable development goals. Sustainability 7: 1651-60.

Ike, Masayoshi, Jerome Denis Donovan, Cheree Topple, and Eryadi Kordi Masli. 2021. Corporate sustainability reporting in Japanese multinational enterprises: A threat to local legitimacy or an opportunity lost for corporate sustainability practices? Multinational Business Review. Unpulished Work. [CrossRef] 
Izzo, Maria Federica, Mirella Ciaburri, and Riccardo Tiscini. 2020. The challenge of sustainable development goal reporting: The first evidence from italian listed companies. Sustainability 12: 3494. [CrossRef]

Jacob, Merle, Mats Lundqvist, and Hans Hellsmark. 2003. Entrepreneurial transformations in the Swedish University system: The case of Chalmers University of Technology. Research Policy 32: 1555-68. [CrossRef]

Jongbloed, Ben, Jürgen Enders, and Carlo Salerno. 2008. Higher education and its communities: Interconnections, interdependencies and a research agenda. Higher Education 56: 303-24. [CrossRef]

Larrán, Manuel, Javier Andrades, and Jesús Herrera. 2018. An examination of attitudes and perceptions of Spanish business and accounting students toward corporate social responsibility and sustainability themes: Análisis de las actitudes y percepciones de los alumnos españoles del ámbito de la empresa y la contabilidad frente a la responsabilidad social y la sostenibilidad. Revista de Contabilidad-Spanish Accounting Review 21: 196-205.

Leal Filho, Walter. 2011. About the role of universities and their contribution to sustainable development. Higher Education Policy 24: 427-38. [CrossRef]

Leal Filho, Walter, Yen-Chun Jim Wu, Luciana Londero Brandli, Lucas Veiga Avila, Ulisses Miranda Azeiteiro, Sandra Caeiro, and Lucia Rejane da Rosa Gama Madruga. 2017. Identifying and overcoming obstacles to the implementation of sustainable development at universities. Journal of Integrative Environmental Sciences 14: 93-108. [CrossRef]

Mattera, Marina, and Carmen Alba Ruiz-Morales. 2021. UNGC principles and SDGs: Perception and business implementation. Marketing Intelligence \& Planning 39: 249-64.

Mattera, Marina, Federico Soto Gonzalez, Carmen Alba Ruiz-Morales, and Luana Gava. 2021. Facing a global crisis—How sustainable business models helped firms overcome COVID. Corporate Governance 21: 1100-16. [CrossRef]

Mawonde, Albert, and Muchaiteyi Togo. 2019. Implementation of SDGs at the University of South Africa. International Journal of Sustainability in Higher Education 20: 932-50. [CrossRef]

Mustaţă, Răzvan Valentin, Carmen Giorgiana Bonaci, Cristina Hintea, and Bogdana Neamţu. 2013. Business education for sustainable development: The case of Romanian universities. Amfiteatru Economic 15: 743-58.

Ndou, Valentina, Giustina Secundo, John Dumay, and Elvin Gjevori. 2018. Understanding intellectual capital disclosure in online media Big Data: An exploratory case study in a university. Meditari Accountancy Research 26: 499-530. [CrossRef]

Nicolò, Giuseppe, Adriana Tiron-Tudor, Francesca Manes-Rossi, and Gianluca Zanellato. 2019. Beyond Financial Reporting: Integrated Reporting and its determinants: Evidence from the context of European state-owned enterprises. Financial Reporting 2: 43-72. [CrossRef]

Nicolò, Giuseppe, Francesca Manes-Rossi, Johan Christiaens, and Natalia Aversano. 2020. Accountability through intellectual capital disclosure in Italian Universities. Journal of Management and Governance 24: 1055-87. [CrossRef]

Nicolò, Giuseppe, Natalia Aversano, Giuseppe Sannino, and Paolo Tartaglia Polcini. 2021a. Investigating Web-Based Sustainability Reporting in Italian Public Universities in the Era of COVID-19. Sustainability 13: 3468. [CrossRef]

Nicolò, Giuseppe, Nicola Raimo, Paolo Tartaglia Polcini, and Filippo Vitolla. 2021b. Unveiling the link between performance and Intellectual Capital disclosure in the context of Italian Public universities. Evaluation and Program Planning 88: 101969.

Oliveira, Lídia, Lúcia Lima Rodrigues, and Russell Craig. 2013. Stakeholder Theory and the Voluntary Disclosure of Intellectual Capital Information. Caspian Journal of Applied Sciences Research 2: 3.

Owens, Taya Louise. 2017. Higher education in the sustainable development goals framework. European Journal of Education 52: 414-20. [CrossRef]

Paletta, Angelo, Pietro Fochi, Tullia Gallina Toschi, and Francesco Ubertini. 2020. Adoption of the SDGs as a Reporting Framework at the Alma Mater Studiorum (University of Bologna) in Italy. In Sustainable Development Goals and Institutions of Higher Education. Cham: Springer, pp. 185-97.

Peña-Sánchez, Antonio Rafael, José Ruiz-Chico, Mercedes Jiménez-García, and José Antonio López-Sánchez. 2020. Tourism and the SDGs: An Analysis of Economic Growth, Decent Employment, and Gender Equality in the European Union (2009-2018). Sustainability 12: 5480. [CrossRef]

Poddar, Anushree, Sapna A. Narula, and Ambika Zutshi. 2019. A study of corporate social responsibility practices of the top Bombay Stock Exchange 500 companies in India and their alignment with the Sustainable Development Goals. Corporate Social Responsibility and Environmental Management 26: 1184-205.

Pop, Nicolae Alexandru, Dan Cristian Dabija, Ionel Dumitru, Corina Monica Pelău, and Eva Cristina Petrescu. 2011. Marketing International: Teorie și Practică. Bucharest: Editura Uranus.

Puertas, Rosa, and Luisa Marti. 2019. Sustainability in universities: DEA Greenmetric. Sustainability 11: 3766. [CrossRef]

Radford, Adam. 2010. A critical assessment of university sustainable development policy: A Gloucestershire case study. Earth $\mathcal{E}$ Environment 8: 210-41.

Santos, Maria João, and Cristina Silva Bastos. 2020. The adoption of sustainable development goals by large Portuguese companies. Social Responsibility Journal 17: 1079-99. [CrossRef]

Sassen, Remmer, and Leyla Azizi. 2018. Voluntary disclosure of sustainability reports by Canadian universities. Journal of Business Economics 88: 97-137. [CrossRef]

SDSN. 2017. SDSN Australia/Pacific 2017: Getting Started with the SDGs in Universities: A Guide for Universities, Higher Education Institutions, and the Academic Sector. Australia, New Zealand and Pacific Edition. Melbourne: Sustainable Development Solutions Network-Australia/Pacific. 
Šebestová, Jarmila, and Włodzimierz Sroka. 2020. Sustainable development goals and SMEs decisions: Czech Republic vs. Poland. Journal of Eastern European and Central Asian Research (JEECAR) 7: 39-50. [CrossRef]

Secundo, Giustina, Mele Gioconda, Pasquale Del Vecchio, Elia Gianluca, Alessandro Margherita, and Ndou Valentina. 2021. Threat or opportunity? A case study of digital-enabled redesign of entrepreneurship education in the COVID-19 emergency. Technological Forecasting and Social Change 166: 120565. [CrossRef]

Sedlacek, Sabine. 2013. The role of universities in fostering sustainable development at the regional level. Journal of Cleaner Production 48: 74-84. [CrossRef]

Sepetis, Anastasios, Aspasia Goula, Niki Kyriakidou, Fotios Rizos, and Marilena G. Sanida. 2020. Education for the Sustainable Development and Corporate Social Responsibility in Higher Education Institutions (HEIs): Evidence from Greece. Journal of Human Resource and Sustainability Studies 8: 86-106. [CrossRef]

The World University Rankings. 2020. Available online: https:/ /www.timeshighereducation.com/world-university-rankings (accessed on 30 June 2020).

Tsalis, Thomas A., Kyveli E. Malamateniou, Dimitrios Koulouriotis, and Ioannis E. Nikolaou. 2020. New challenges for corporate sustainability reporting: United Nations' 2030 Agenda for sustainable development and the sustainable development goals. Corporate Social Responsibility and Environmental Management 27: 1617-29. [CrossRef]

UN-United Nations. 2015. Transforming Our World: The 2030 Agenda for Sustainable Development. New York, NY: UN-United Nations, Available online: https:/ / sustainabledevelopment.un.org (accessed on 2 June 2021).

UNWCED—United Nations World Commission on Environment and Development. 1987. Our Common Future (The Brundtland Report). Oxford: Oxford University Press.

Waas, Tom, Aviel Verbruggen, and Tarah Wright. 2010. University research for sustainable development: Definition and characteristics explored. Journal of Cleaner Production 18: 629-36. [CrossRef]

Wakkee, Ingrid, Peter. van der Sijde, Christiaan Vaupell, and Karminder Ghuman. 2019. The university's role in sustainable development: Activating entrepreneurial scholars as agents of change. Technological Forecasting and Social Change 141: 195-205. [CrossRef]

Weber, Heloise. 2017. Politics of 'leaving no one behind': Contesting the 2030 Sustainable Development Goals agenda. Globalizations 14: 399-414. [CrossRef]

Yin, Robert K. 2017. Case Study Research and Applications: Design and Methods. Los Angeles, CA: Sage Publications.

Youtie, Jan, and Philip Shapira. 2008. Building an innovation hub: A case study of the transformation of university roles in regional technological and economic development. Research Policy 37: 1188-204. [CrossRef] 